\title{
Operationalizing the Role of Context in Language Variation: The Role of Perspective Alignment in the Spanish Imperfective Domain
}

\author{
Martín Fuchs, María Mercedes Piñango, and Ashwini Deo
}

\begin{abstract}
We present a cognitively grounded analysis of the pattern of variation that underlies the use of two aspectual markers in Spanish (the Simple-Present marker, Ana baila 'Ana dances', and the Present-Progressive marker, Ana está bailando 'Ana is dancing') when they express an event-in-progress reading. This analysis is centered around one fundamental communicative goal, which we term perspective alignment: the bringing of the hearer's perspective closer to that of the speaker. Perspective alignment optimizes the tension between two nonlinguistic constraints: Theory of Mind, which gives rise to linguistic expressivity, and Common Ground, which gives rise to linguistic economy. We propose that, linguistically, perspective alignment capitalizes on lexicalized meanings, such as the progressive meaning, that can bring the hearer to the "here and now". In Spanish, progressive meaning can be conveyed with the Present-Progressive marker regardless of context. By contrast, if the Simple-Present marker is used for that purpose, it must be in a context of shared perceptual access between speaker and hearer; precisely, a condition that establishes perspective alignment non-linguistically. Support for this analysis comes from a previously observed yet unexplained pattern of contextually-determined variation for the use of the Simple-Present marker in Iberian and Rioplatense (vs. Mexican) Spanish - in contrast to the preference across all three varieties for the use of the Present-Progressive marker-to express an event-in-progress reading.
\end{abstract}

Keywords Imperfective $\cdot$ Progressive $\cdot$ Expressivity $\cdot$ Economy $\cdot$ Common Ground $\cdot$ Theory of mind $\cdot$ Meaning variation and change

\footnotetext{
M. Fuchs $\cdot$ M. M. Piñango

Department of Linguistics, Yale University, New Haven, USA

Present Address:

M. Fuchs ( $\varangle)$

Utrecht Institute of Linguistics - OTS, Utrecht University, Trans 10, Utrecht 3512JK,

The Netherlands

e-mail: m.fuchs@uu.nl
}

\author{
A. Deo \\ Department of Linguistics, The Ohio State University, Columbus, USA \\ (C) The Author(s) 2021 \\ S. Löbner et al. (eds.), Concepts, Frames and Cascades in Semantics, \\ Cognition and Ontology, Language, Cognition, and Mind 7, \\ https://doi.org/10.1007/978-3-030-50200-3_10
}




\section{Introduction}

Successful linguistic communication occurs when a speaker utters an expression and a comprehender recognizes the specific meaning that the speaker intended to convey by uttering that expression. If all markers in a linguistic system were in a strict one-to-one correspondence to a meaning, linguistic communication would always be unambiguous. However, that is rarely the case; linguistic markers usually make more than one type of contribution to the composed sentential meaning, leading to different readings of the expressions of which they are part. That is because the markers' associated meanings are encoded in such a way that they demand interaction with a context in order to be properly composed with the other meanings in the expression (e.g., Lewis 1980; Kaplan 1989).

From a communicative perspective, the interaction between linguistic meaning and nonlinguistic context is manifested as a tension between how much meaning is predictably associated with a marker (i.e., lexicalized) and how much meaning must be retrieved from the contextual information in the communicative situation. While the former leads to expressivity - the requirement that all intended meaning be linguistically encoded - , the latter leads to economy - the possibility that meaning be inferred from the shared history of the interlocutors and the properties of the physical environment where communication takes place at a given time. This tension appears to be rooted in fundamental human cognitive biases: on the one hand, speakers want to be able to convey specific meanings to their hearers; on the other hand, they want to do so by uttering the least amount of linguistic information, relying instead on the contextual properties that constrain the hearer's interpretation. How are lexical meanings structured such that this tension is resolved, leading to the fast-paced, seemingly transparent, communication process that is typically observed?

We propose that this question can be addressed by investigating meaning variation; that is, the systematic ways in which a marker shifts its connection to a meaning across members of the same speech community. We hypothesize here that meaning variation for a given marker ultimately results from specific communicative and cognitive pressures in interaction with the contextual demands of that marker. We focus on grammatical aspect, a component of the grammar that is subject to variation and ultimately diachronic change (Dahl 1985; Bybee et al. 1994, i.a.); specifically, on the Imperfective aspectual domain in Spanish.

The Spanish Imperfective aspectual domain is a good test case for analyzing the properties that determine meaning variation given that it is expressed by the Present-Progressive marker and the Simple-Present marker, two markers that convey two readings - the event-in-progress and the habitual-in a two-by-two system. ${ }^{1,2}$

\footnotetext{
${ }^{1}$ In this paper, we explore the Imperfective domain in the Present tense, but we assume that the conclusions that we put forth also hold in a similar way for the imperfective and progressive meanings in the Past and Future tenses.

${ }^{2}$ These markers are also able to express a continuous reading when they are combined with lexically stative predicates, such as in Ana vive en Bogotá ('Ana lives in Bogotá') or as in Ana está viviendo en Bogotá ('Ana is living in Bogotá'). We leave this reading aside for the purposes of this paper.
} 
The alternations between these two markers also manifest a shared semantic structure between the two meanings that participate in this aspectual domain, in which the progressive meaning is a subcase of the more general imperfective meaning (Kurylowicz 1964; Comrie 1976; Deo 2009, i.a.).

In previous work (Fuchs et al. 2020) we have shown that in Spanish, contrary to traditional assumptions (e.g., Marchand 1955; Bertinetto 2000), these two markers are not in free variation, and that when it comes to the expression of the event-inprogress reading, their use appears to be governed by contextual constraints. Here, we present a theoretical model of that variability that is cognitively rooted in the communicative factors involved in those contextual constraints and in the structure of the subsystem(s) to which those communicative factors belong. This model gives rise to an account whereby the recognition of a progressive meaning implicates the alignment of the hearer's perspective to that of the speaker. We argue that this alignment can be obtained both by linguistic and by non-linguistic means, and we show that the tension between the use of the Present-Progressive marker and the SimplePresent marker in Spanish to convey an event-in-progress reading is a direct result of whether the alignment of the speaker's and the hearer's perspectives was already introduced by non-linguistic means, or whether it needs to be encoded linguistically.

The remainder of this paper is structured as follows. Section 2 describes the distribution of the Present-Progressive marker and the Simple-Present marker in Modern Spanish. Section 3 presents the formal structures we are assuming for the progressive and the imperfective meanings, together with their communicative implications, and a proposal for a unified meaning structure of these two meanings that allows for the observed systematic variation in their use. Section 4 presents the previously reported data in Fuchs et al. (2020) on the markers' context-modulated behavior in three Spanish varieties for the event-in-progress reading. Section 5 presents the analysis based on the data introduced in $\S 4$. Section 6 concludes the paper.

\section{On the Spanish Present-Progressive and Simple-Present Markers}

Spanish has two markers that express the Imperfective aspectual domain in the Present: the periphrastic Present-Progressive marker in (1a), constituted by the verb estar 'to be' plus the gerund $V+-n d o$, and the syncretic Simple-Present marker in (1b) (Yllera 1999; NGRAE 2009, i.a.).

$\begin{array}{rll}\text { (1) a. Ana est-á } & \text { fum-ando } & \text { (ahora). } \\ \text { Ana be-PRS.3.SG smoke-PROG } & \text { (now) } \\ \text { 'Ana is smoking now' } & \\ \text { b. Ana fum-a } & \text { ahora. } \\ \text { Ana smoke-PRS.3.SG } & \text { now } \\ \text { 'Ana is smoking now' } & \end{array}$


In (1) these markers are supporting an event-in-progress reading; that is, their contribution to the sentential meaning leads to the interpretation that the event described by the predicate is unfolding at reference time. However, both of these markers can also convey a more general imperfective meaning, that, for instance, can give rise to a habitual reading; that is, their contribution to the sentential meaning leads to the interpretation that the event described by the predicate has regular instantiations over some interval of time, as in (2).

$\begin{array}{lllll}\text { a. Ana est-á fum-ando todos los días. } & \text { lons. } \\ \text { Ana be-PRS.3.SG smoke- PROG all the } & \text { days. } \\ \text { 'Ana is smoking every day' } & & & \\ \text { b. Ana fum-a } & \text { todos los } & \text { días. } \\ \text { Ana smoke-PRS.3.SG } & \text { all the } & \text { days } \\ \text { 'Ana smokes every day' } & & & \end{array}$

The sentences in (1) and (2) show that, given different discourse or situational contexts, both the Present-Progressive marker and the Simple-Present marker can each alternatively convey an event-in-progress or a habitual reading. This situation raises at least two questions: (1) How are these different readings connected such that this alternation can obtain? (2) If contextual constraints are involved in the observed distribution of the markers, what specific contextual factors are modulating the variation? The answer to these questions is the focus of the next two sections.

\section{The Meaning of the Progressive and the Imperfective: A Communicative Perspective}

Aspect is said to be the grammatical category that expresses how a situation extends over time; from a communicative viewpoint, we can conceive it as a part of the way in which speakers and hearers experience and schematize the world. This experience gets encoded in linguistic devices both lexically and grammatically (e.g., Vendler 1957; Verkuyl 1972; Comrie 1976).

Imperfective aspect denotes a property of a situation whereby the situation is understood as continuing throughout some interval of time. In language-neutral terms, for a sentence to have imperfective aspect, it necessarily and sufficiently needs to present the Subinterval Property; that is, if a predicate $P$ is true at some interval $I$, it follows that the predicate $P$ is true at all (relevant) subintervals of $I$.

Both the event-in-progress and the habitual readings of the Spanish Imperfective aspectual domain show the Subinterval Property. The sentence radical (smoke(Ana)) in both sentences in (1), repeated here as (3), holds of every relevant subinterval of the reference interval (i.e., now in those sentences). ${ }^{3}$ In the case of the sentences in

\footnotetext{
${ }^{3}$ We understand sentence radicals to be predicates of eventualities with their arguments saturated.
} 
(2), repeated here as (4), the sentence radical in both sentences holds at all relevant regular subintervals of the interval under consideration, which is a superinterval of the reference interval.

$\begin{array}{ll}\text { a. Ana est-á fum-ando } & \text { (ahora). } \\ \text { Ana be-PRS.3.SG smoke-PROG } & \text { (now) } \\ \text { 'Ana is smoking now' } & \\ \text { b. Ana fum-a } & \text { ahora. } \\ \text { Ana smoke-PRS.3.SG } & \text { now } \\ \text { 'Ana is smoking now' } & \end{array}$

(4)

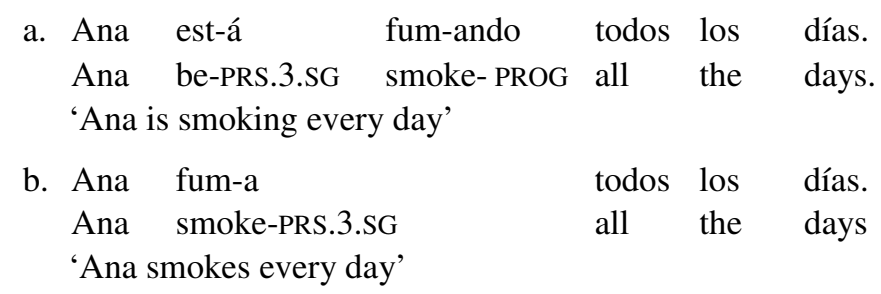

Deo $(2009,2015)$ provides a unified account of the progressive and the imperfective meanings that allows for the availability of the event-in-progress and habitual readings. Under this account, the progressive and the imperfective meanings are encoded as two distinct operators that apply to predicates of eventualities denoted by sentence radicals. This proposal treats the meaning of the progressive operator as a subset of the meaning of the imperfective operator (see also Kurylowicz 1964; Comrie 1976, i.a.). Both operators involve a universal quantifier whose domain of quantification is a regular partition of an interval; i.e., a set of collectively exhaustive, non-overlapping, equimeasured subsets of some set, against which the instantiation of a given predicate is evaluated regarding its distribution over time. The notion of instantiation of a predicate over regular partitions of an interval captures the intuition of a regular distribution over time that obtains with utterances with imperfective aspect. Key to this analysis is that the measure of the regular partition, which determines the value of each cell of the partition, is a free variable with a contextually-determined value. The different readings that each meaning presents are thus the result of different values in different contexts.

The contrast between the two operators emerges from differences in their respective domains of quantification: while in the case of the progressive operator, the domain of quantification is a regular partition of the reference interval (that is, the predicate stands in a coincidence relation ${ }^{4}$ with regular subintervals of the reference

\footnotetext{
${ }^{4}$ The coincidence relation is defined as follows: "a predicate of events stands in the coincidence relation with an interval $i$ and a world $w$ if and only if $P$ is instantiated in every inertial alternative of $w$ within $i$ or at some superinterval of $i$ " (Deo 2015: 11). Inertia worlds are understood as in Dowty (1977); i.e., as the worlds that continue beyond $i$ in ways that are compatible with the regular course of events until $i$. Inertia worlds thus allow the coincidence relation to avoid the Imperfective
} 
interval), in the case of the imperfective operator, the domain of quantification is a regular partition of a superinterval of the reference interval (that is, the predicate stands in a coincidence relation with regular subintervals of a superinterval of the reference interval). Thus, the progressive meaning behaves as a subset of the imperfective meaning: the reference interval is always a subinterval of a superinterval of itself. The formal representations for each of these operators, taken from Deo (2015), are given below:

$$
\begin{aligned}
& P R O G: \lambda P \lambda i \lambda w \cdot \forall j\left[j \in \mathscr{R}_{i}^{c} \rightarrow \operatorname{COIN}(P, j, w)\right] \\
& I M P F: \lambda P \lambda i \lambda w \cdot \exists j\left[i \subseteq_{i n i} j \wedge \forall k\left[k \in \mathscr{R}_{j}^{c} \rightarrow \operatorname{COIN}(P, k, w)\right]\right]
\end{aligned}
$$

The progressive operator combines with a predicate of eventualities $P$ and an interval $i$ and returns the proposition that every cell $j$ of a regular partition of $i$ coincides with $P$. The imperfective operator, on the other hand, combines with a predicate of eventualities $P$ and an interval $i$, and returns the proposition that there is some interval $j$ that continues $i$ such that every cell $k$ of a regular partition of $j$ coincides with $P$.

Here we argue that the subset organization dependent on the relation between a reference interval and a superinterval thereof has communicative implications that are observable in specific usage patterns, such as the ones described in $§ 2$. Specifically, we propose that the interval structure that underlies both operators constitutes a unified conceptual structure whose variables are the interval under consideration and the measure of the regular partition. ${ }^{5}$ The interactions between these two variables give rise to the event-in-progress or the habitual readings of the different meanings. In what follows, we discuss each meaning and their communicative implementations. ${ }^{6}$

In the case of the progressive, the domain of quantification is the reference interval. When the hearer comprehends a progressive sentence with an event-in-progress reading, such as the sentences in (1), the marker triggers the representation of an interval, the reference interval, as we see in Fig. 1.

This interval is constituted by regular partitions, as we observe in Fig. 2. What the operator demands is that every cell $j$ be of a regular partition of $i$.

At this point, what is left for the hearer's parser is to map the associated proposition $P$ to every cell $j$ of a regular partition of that interval $i$ in that world of evaluation $w$, making it coincide with them, as it can be seen in the visual representation and the formula in Fig. 3.

Paradox. Throughout the remainder of the paper, this is the definition of the coincidence relation assumed. We simplify its presentation for reasons of space.

${ }^{5}$ The status of a 'conceptual structure' for this meaning structure manifests our deeper claim that this unified meaning is not a linguistic device, but a substructure of a larger nonlinguistic cognitive system to which language has access through imperfective and progressive markers.

${ }^{6}$ The incremental presentations of the communicative implementations of the meanings of the progressive and the imperfective are not a claim about their processing. They are simply visual devices that illustrate the meaning structure to which the markers have access. 


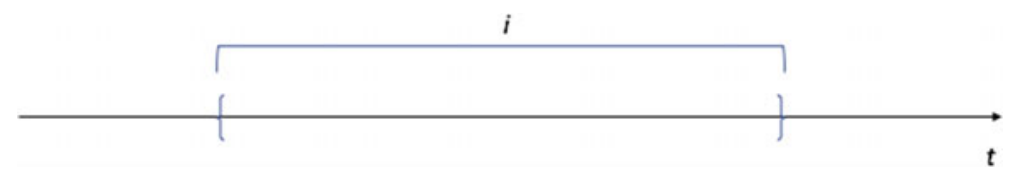

Fig. 1 The progressive meaning from a communicative perspective (1/3)

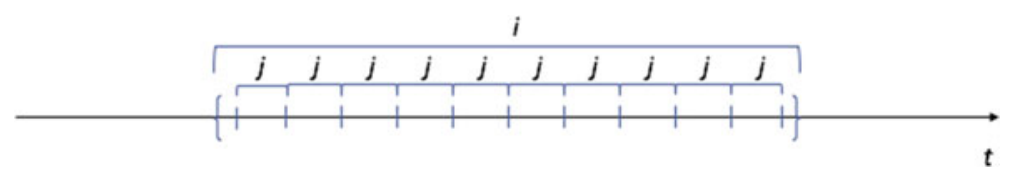

Fig. 2 The progressive meaning from a communicative perspective $(2 / 3)$

$$
P R O G: \lambda P \lambda i \lambda w . \forall j\left[j \in \mathscr{R}_{i}^{c} \rightarrow \operatorname{COIN}(P, j, w)\right]
$$

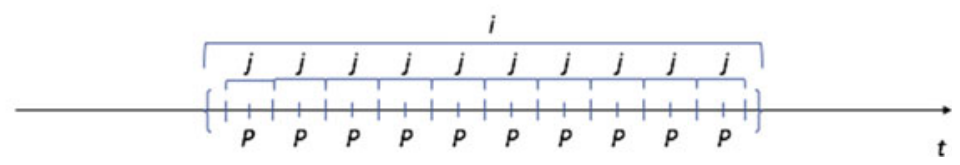

Fig. 3 The progressive meaning from a communicative perspective (3/3)

Therefore, a sentence such as (1a), Ana está fumando ahora, 'Ana is smoking now', would be represented from a communicative perspective as in Fig. 4, where the sentence radical (Smoke(Ana)), ( $\mathrm{S}(\mathrm{A})$ ), is mapped to every cell of a regular partition of the reference interval.

In the case of the imperfective, the domain of the quantifier is a superinterval of the reference interval. This allows for the appearance of the habitual reading. From the perspective of communication, when a hearer receives an imperfective sentence with a habitual reading, it not only triggers the representation of an interval $i-$ the reference interval-, but also of the associated superinterval $j$, as it can be seen in Fig. 5.

Just like the reference interval, this superinterval is constituted by regular partitions, as we observe in Fig. 6. What the operator demands is that every cell $k$ be of a regular partition of $j$.

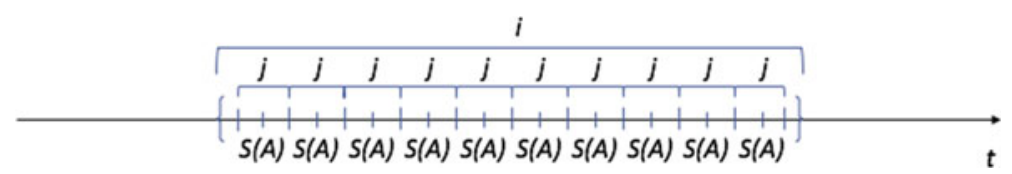

Fig. 4 The representation of Ana está fumando ahora 'Ana is smoking now' from a communicative perspective 


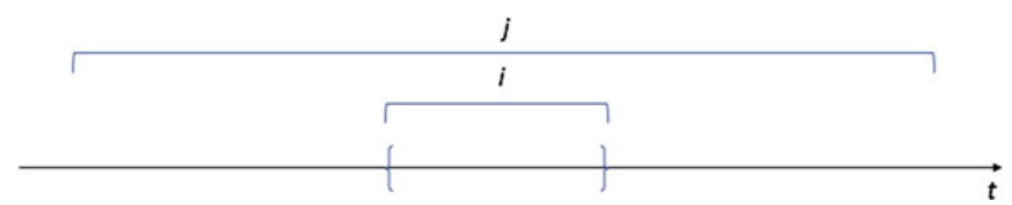

Fig. 5 The imperfective meaning from a communicative perspective (1/3)

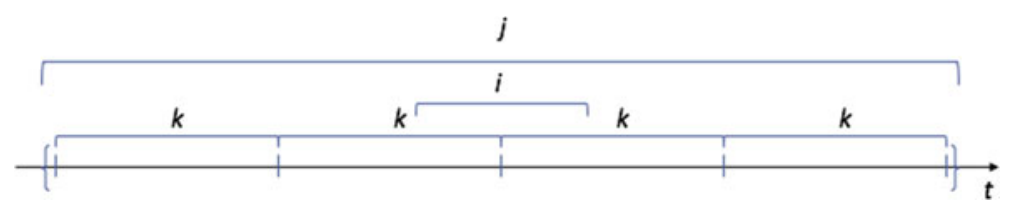

Fig. 6 The imperfective meaning from a communicative perspective (2/3)

The role of the hearer's parser in this case is to map the proposition $P$ to every cell $k$ of a regular partition of that superinterval $j$ in that world of evaluation $w$, making it coincide with them. This is presented in Fig. 7.

Accordingly, from a communicative perspective, a sentence such as (2b), Ana fuma todos los días, 'Ana smokes every day', is represented as in Fig. 8. In this case, the sentence radical (Smoke (Ana)), $(\mathrm{S}(\mathrm{A}))$, is mapped to every cell $k$ of a regular partition of $j$.

$\operatorname{IMPF}: \lambda P \lambda i \lambda w . \exists j\left[i \subseteq_{i n i} j \wedge \forall k\left[k \in \mathscr{R}_{j}^{c} \rightarrow \operatorname{COIN}(p, k, w)\right]\right]$

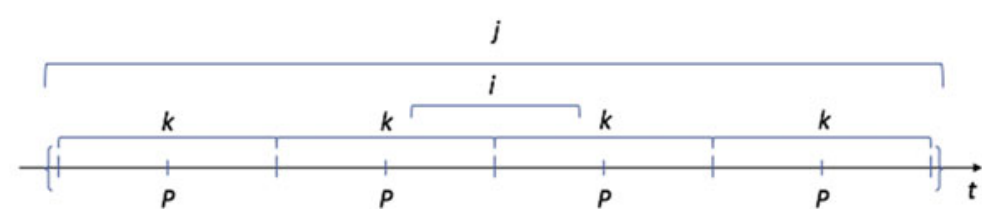

Fig. 7 The imperfective meaning from a communicative perspective (3/3)

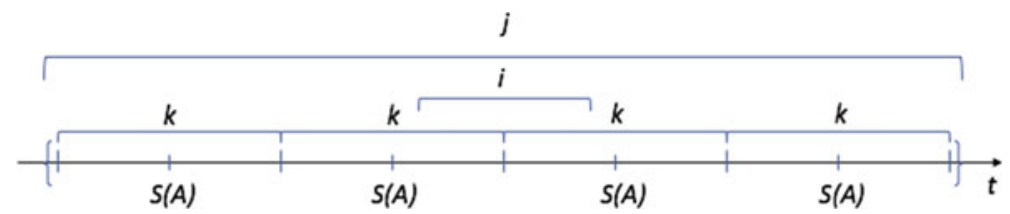

Fig. 8 The representation of Ana fuma todos los días 'Ana smokes every day' from a communicative perspective 


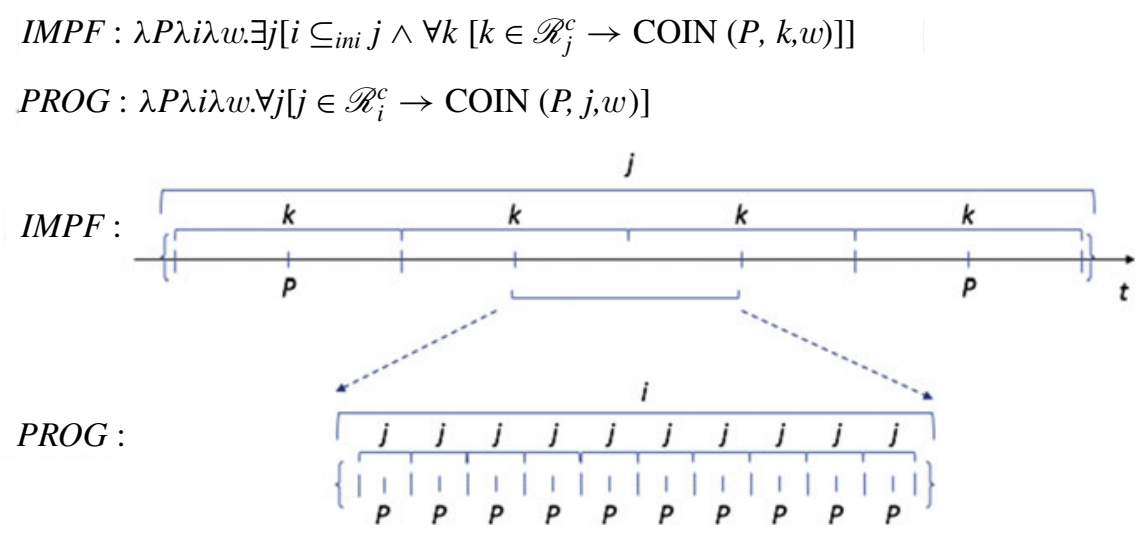

Fig. 9 The meaning structure of the imperfective domain: the imperfective (above) and the progressive (below)

In Fig. 9 below, these two readings of the Imperfective aspectual domain-the event-in-progress and the habitual-emerge from the same meaning structure: a predicate of events coincides with every cell of a regular partition of an interval. They differ only in the components of the meaning structure that each reading makes salient: while the habitual reading makes salient both levels within the structure (the reference interval and a superinterval thereof), the event-in-progress reading makes salient the reference interval alone.

\section{The Markers of the Spanish Progressive Are not in Free Variation: Implications}

In previous work, we report experimental evidence consistent with the possibility that the Present-Progressive and the Simple-Present markers are not in free variation when conveying an event-in-progress reading, and that the choice of marker is in fact contextually determined (Fuchs et al. 2020). In this section, we summarize those results. The data pattern that is presented in that paper serves as a clear test case for our communicative analysis and for testing the implications of a unified conceptual structure for both the progressive and the imperfective meanings of the Imperfective aspectual domain.

Fuchs et al. (2020) reports data from a sentence acceptability judgment task. A total of 114 participants from three different Spanish dialectal varieties rated on a 1-to-5 Likert scale context-sentence pairs that induced an event-in-progress reading with either the Present-Progressive marker, the Simple-Present marker, or the SimplePast marker (used as a baseline condition). Target sentences were preceded either by a context that indicated that speaker and hearer had equivalent perceptual access to the event described by the predicate (Rich Context) or by a context that indicated 
that the speaker and the hearer did not share perceptual access to the event (Poor Context). Shared perceptual access was operationalized as visual perceptual access: both participants in the discourse situation were observing the event that the predicate in the target sentence described. An example of each type of context is presented in (5) and (6) respectively.

\section{Rich Context}

(5) Ana llega a su casa de trabajar y va a buscar a su hijo a su habitación. Golpea la puerta, la abre, y ve al hijo sentado en el escritorio. Antes de que ella diga nada, el hijo le dice:

'Ana comes home from work, and goes to her son's room to look for him. She knocks on the door, opens it, and sees him sitting at his desk. Before she says anything, her son tells her:'

\section{Poor Context}

(6) Ana llega a su casa de trabajar y va a buscar a su hijo a su habitación. Golpea la puerta, pero el hijo no contesta. Sin que ella llegue a abrir la puerta, el hijo le dice:

'Ana comes home from work, and goes to her son's room to look for him. She knocks on the door, but her son does not answer. Before she gets to open the door, her son tells her:'

Each of these contexts was then followed by a target sentence that the participant had to rate, which presented either the Present-Progressive marker (7a), the SimplePresent marker (7b), or the Simple-Past marker (7c).
a. Est-oy haci-endo la tarea.
be-PRS.1.SG do-PROG the homework
'I am doing homework'
b. Hag-o la tarea.
do-PRS.1.SG the homework.
'I am doing homework'
c. Hi-ce la tarea.
do-PST.1.SG the homework
'I did homework'

The study was originally designed to test two competing hypotheses regarding the variation between these markers to express an event-in-progress reading: a free alternation hypothesis, which argued that the markers could be used interchangeably regardless of the type of context, and a context dependent hypothesis, which stated 
Table 1 Participants' ratings means and standard errors by condition (dialect * aspectual marker * context)

\begin{tabular}{l|l|l|l|l|l|l}
\hline & \multicolumn{2}{|l|}{ Iberian Spanish } & \multicolumn{2}{l|}{ Rioplatense Spanish } & \multicolumn{2}{l}{ Mexican Alt. Spanish } \\
\hline & Rich & Poor & Rich & Poor & Rich & Poor \\
\hline P. PROG & $4.78(0.03)$ & $4.74(0.03)$ & $4.68(0.05)$ & $4.66(0.05)$ & $4.51(0.06)$ & $4.46(0.06)$ \\
\hline S. PRESENT & $\mathbf{4 . 1 8 ( 0 . 1 1 )}$ & $\mathbf{3 . 7 0}(\mathbf{0 . 0 9})$ & $\mathbf{3 . 9 0}(\mathbf{0 . 1 1})$ & $\mathbf{3 . 4 3 ( 0 . 0 8 )}$ & $3.57(0.12)$ & $3.51(0.12)$ \\
\hline S. PAST & $2.16(0.08)$ & $2.15(0.09)$ & $2.67(0.08)$ & $2.57(0.08)$ & $2.67(0.09)$ & $2.63(0.08)$ \\
\hline
\end{tabular}

that the choice of marker was conditioned by properties of the contextual information. We proposed that marker use was context-dependent, and that its locus of variation was shared perceptual access to the event between the speaker and the hearer. ${ }^{7}$

The three varieties of Spanish probed were Mexican Altiplano Spanish (Mexico City), Iberian Spanish (Madrid), and Rioplatense Spanish (Buenos Aires) with similar participant distributions: 39 (20 female) Iberian Spanish speakers; 38 (21 female) Rioplatense Spanish speakers, and 37 (21 female) Mexican Altiplano Spanish speakers. ${ }^{8}$ The rationale for testing different varieties was that the Imperfective aspectual domain could be partitioned by these markers in different yet predictable ways in each of the dialects.

A summary of the results in terms of the participants' ratings means by context, aspectual marker and dialect is given in Table 1. Standard errors are indicated in parentheses. Conditions where there are significant differences are bolded.

In all three Spanish varieties, the Present-Progressive marker is the preferred form to express an event-in-progress reading regardless of contextual information, while the Simple-Past form is disallowed from expressing an event-in-progress reading

\footnotetext{
${ }^{7}$ With respect to the Simple-Present marker, we tested the prediction associated with the context dependent hypothesis. According to this hypothesis, when the situational context presents information that shows that speaker and hearer share perceptual access to the event described by the predicate, the Simple-Present marker should get significantly higher ratings than when the information in the situational context does not indicate that speaker and hearer share perceptual access to the situation at issue.

Regardless of the issue of context-dependence, we expected the Present-Progressive marker in every dialect to obtain ceiling ratings, as the Present-Progressive marker exhibits the event-inprogress as its most salient reading. Our analysis argued that this occurred because the PresentProgressive marker was unambiguous in conveying an event-in-progress reading. That analysis, however, was incomplete in that it did not take into account the habitual reading of the PresentProgressive marker, such as the one in (2a), Ana está fumando todos los días 'Ana is smoking every day', whose existence evidences that the locus of the variation is not necessarily presence/absence of ambiguity in marker-meaning correspondence, but something else that relates the structure of the meaning itself (i.e., the progressive) to its communicative implications.

The model we present here accounts for the presence of ambiguity by arguing that while the Present-Progressive marker may be preferentially lexically associated with the progressive meaning, given the shared conceptual structure described in $\S 3$, it also has the potential to access the other readings. It does so by allowing modification of the measure of the regular partition-and, in this way, referring to a superinterval of the reference interval-, thus achieving a habitual interpretation. Unfortunately, more extensive discussion of these cases is beyond the scope of this paper.

${ }^{8}$ For details on the procedure, see Fuchs et al. (2020), §4.2.
} 

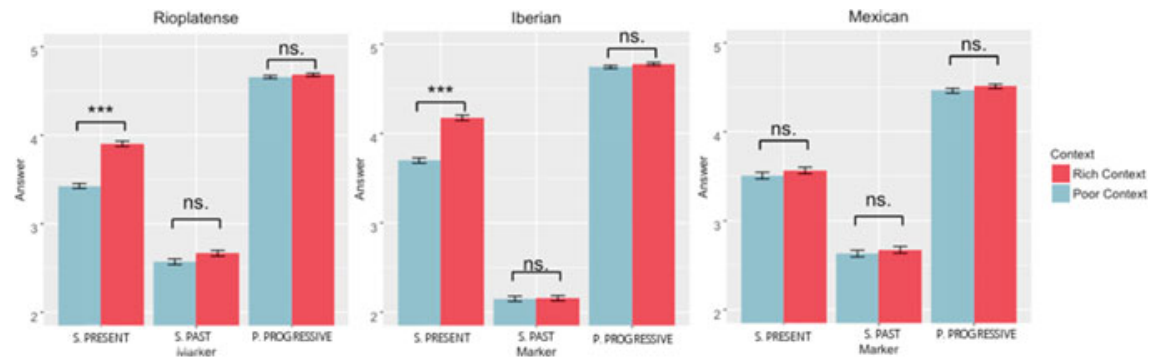

Fig. 10 Participants' means by context condition, aspectual marker and dialect

across the board. With respect to the Simple-Present marker, in at least Rioplatense and Iberian Spanish, the acceptability of the marker appears to be modulated by contextual information. When the speaker and the hearer share perceptual access to the event described by the predicate, participants judge the use of the Simple-Present marker as significantly more acceptable than when the speaker and the hearer do not share perceptual access to the event. In the case of Mexican Altiplano Spanish, the Simple-Present marker is dispreferred with respect to the Present-Progressive marker regardless of contextual information. ${ }^{9}$ A graph of the participants' ratings by contextual information, marker and dialect is presented in Fig. 10.

These results show that the use of the Simple-Present marker to convey an eventin-progress reading is restricted by context in at least two dialects of SpanishRioplatense and Iberian Spanish. Therefore, the data show that the markers do not alternate freely, and provide support to the context dependent hypothesis. While the Present-Progressive marker is the preferred form to convey an event-in-progress reading across the three dialectal varieties and regardless of contextual information, the Simple-Present marker is context-dependent and its acceptability is modulated by the assessment that participants make of the shared perceptual access between speaker and hearer conveyed in the preceding context. We also observe that this context-dependence is subject to dialectal variation: while Rioplatense and Iberian Spanish show context-dependence in their use of the Simple-Present marker, Mexican Altiplano Spanish presents a distribution in which this contextual distinction becomes irrelevant, and the only mean to achieve the event-in-progress reading is linguistic; that is, the use of the Present-Progressive marker.

\footnotetext{
${ }^{9}$ For a detailed explanation of why the dialects differ, and how this variation is constrained by a unidirectional diachronic grammaticalization path from Progressive to Imperfective, see Fuchs et al. (2020), §2.2., and §6.
} 


\section{Analysis: The Psychological Roots of Shared Perceptual Access}

The pattern described in $\$ 4$ shows that the distribution between the PresentProgressive marker and the Simple-Present marker in the expression of the event-inprogress reading is not haphazard, but governed by contextual constraints; namely, by whether the speaker and the hearer share perceptual access to the event described by the predicate.

In this section, we present an analysis of this contextual factor that is couched in terms of general communicative and cognitive constraints. Our proposal is based on the notion of perspective, understood as the information that is perceptually available for a given individual from a particular point of view in space (Roberts 2015: 3). This perspective, moreover, is doxastic in that it is understood to be the set of worlds compatible with an individual's beliefs at that time in that world. From a communicative perspective, we consider that grammatical aspect not only reflects the point of view of the speaker, but it is also able to manipulate it, in a process that we call perspective alignment. In this process, which we consider to be one of the general goals of communication, the speaker intends to align the hearer's (doxastic) perspective to her own; that is, she intends to make the worlds compatible with the hearer's beliefs more like the worlds compatible with her own beliefs.

We propose perspective alignment as the resolution of the well-known tension between linguistic economy and linguistic expressivity during communication (Zipf 1949). We take these two factors to be epiphenomenal: manifestations of different kinds of knowledge. On the one hand, linguistic economy reflects a speaker's expectation about the hearer that, given their shared history, their minds' perception and schematization of the world are the same. This expectation allows the speaker to make her utterances shorter, containing more lexical items with underspecified meanings. Linguistic economy is thus a manifestation of the Common Ground, the shared context between interlocutors during a given linguistic communicative act (Stalnaker 1978, 2002; Roberts 1996/2012 i.a.). It is the speaker's expected common ground with the hearer that allows for linguistic economy.

Linguistic expressivity, on the other hand, reflects the speaker's knowledge that the hearer is a separate individual and that consequently their minds may overlap but are not identical and are not necessarily experiencing and schematizing the context at issue in the same manner. From a linguistic communicative perspective, this knowledge amounts to Theory of Mind (Wellman 1990; Gopnik 1993; de Villiers 2007, i.a.). This understanding compels the speaker to encode linguistically all of her intended meaning, leading to linguistic expressivity.

Under these two notions, linguistic economy appears as speaker-oriented, while linguistic expressivity appears as hearer-oriented. Thereby lies the communicative tension that clarifies the objective of linguistic communication: the bringing of the hearer to the point of view or perspective of the speaker. And this, in a nutshell, is what perspective alignment seeks: the optimization of Common Ground and Theory of Mind constraints between speaker and hearer during the communicative act. 
We argue that, linguistically, perspective alignment can be achieved by lexicalized meanings, such as the progressive meaning, that bring the hearer to the "here and now". The progressive meaning makes salient the reference interval in the shared meaning structure (described in §3) — thus conveying information about the "here and now"-, and in doing so, it brings the perspective of the hearer closer to that of the speaker.

Under this analysis, when intending to convey a progressive meaning in a language with two distinct markers whose alternation is contextually determined-such as present-day Spanish-, the speaker has either the choice of relying on non-linguistic contextual information and use the Simple-Present marker or the choice of using the Present-Progressive marker. In order to felicitously utter a sentence with a SimplePresent marker that conveys a progressive meaning, the speaker needs to know that the hearer has perceptual access to the situation described by the embedded proposition. This condition-shared perceptual access-constraints the interpretation to the reference interval, satisfying the requirements of the progressive meaning, and brings about perspective alignment by non-linguistic means. If the speaker cannot know whether the hearer has perceptual access to the situation described by the embedded proposition, perspective alignment is not met non-linguistically, and the Present-Progressive marker must be used instead. In this way, perspective alignment can be provided both non-linguistically (by contextual information) or linguistically (by the use of the Present-Progressive marker).

This is what the pattern uncovered in Fuchs et al. (2020) ultimately shows: that the acceptability of the Simple-Present marker to convey a progressive meaning increases in Rioplatense and Iberian Spanish, but only when the situational context expresses that there is shared perceptual access to the event between speaker and hearer, guaranteeing non-linguistically speaker-hearer perspective alignment. Conversely, in cases in which the information given in the situational context does not indicate that there is shared perceptual access to the event between speaker and hearer, and perspective alignment is not provided non-linguistically, the acceptability of the Simple-Present marker decreases significantly. In these cases, the speaker needs to assume that the hearer can only rely on linguistic information to comprehend the intended meaning that she wants to convey, and resort to the Present-Progressive marker. In sum, the Simple-Present marker can be used to convey a progressive meaning only when the communicative goal of perspective alignment is achieved independently.

Finally, even in rich contexts, where perspective alignment is non-linguistically guaranteed, we observe that the Present-Progressive marker gets higher ratings than the Simple-Present marker. We account for this pattern by invoking a key property of language: lexicalization as a means to faster processing. The Present-Progressive marker, by its preferred reference interval interpretation (progressive), has in a way lexicalized perspective alignment. ${ }^{10}$ By contrast, the use of the Simple-Present marker to reach perspective alignment demands the incorporation of non-linguistic

\footnotetext{
${ }^{10}$ We claim that this is true not only for the sentences in which the Present-Progressive marker conveys a progressive meaning, but also for sentences such as (2a), Ana está fumando todos los días 'Ana is smoking every day', where the Present-Progressive marker does not express an eventin-progress reading, but a habitual one with a temporal contingency. In these cases, perspective
} 
information, which ultimately needs to be integrated into a unified meaning structure. As comprehension progresses, such real-time integration of linguistic and contextual information is arguably computationally costlier. And it is the avoidance of this cost what finally leads speakers to systematically prefer Present-Progressivemarked utterances. An extreme version of this situation is shown by the Mexican Altiplano Spanish variety, in which the Simple-Present marker is dispreferred to convey a progressive meaning even when the context provides perspective alignment by non-linguistic means.

\section{Summary and Conclusions}

Here we have provided a cognitively grounded approach to non-linguistic context modeling, and an account of how contextual factors interact with linguistic information in the process of sentence meaning comprehension. We have capitalized on a pattern previously reported (Fuchs et al. 2020), which shows that across two varieties of Spanish the acceptability of the Simple-Present marker to convey a progressive meaning is modulated by whether or not the speaker and the hearer share perceptual access to the situation described by the proposition at issue.

We have shown that this contextual factor can be captured by appealing to a core communicative goal: perspective alignment. This communicative goal is taken to be the optimization of the tension between linguistic economy-rooted in Common Ground-and linguistic expressivity—rooted in Theory of Mind. The connections with deeper cognitive capacities render shared perceptual access not a primitive, but the non-linguistic operationalization of this generalized communicative objective, perspective alignment. As the data show, shared perceptual access is necessary whenever the linguistic marker cannot bring about perspective alignment on its own. Such is the case of the Spanish Simple-Present marker when it is conveying progressive meaning. By contrast, when the linguistic marker is the Spanish PresentProgressive marker, it can signal perspective alignment on its own. In doing so it presents two communicative advantages: (1) it makes communicative success more predictable, and therefore efficient, since its use is now less context-dependent, and (2) it demands less computational resources: it saves the processor the cost of integrating the linguistic content and the non-linguistic contextual information that it would otherwise need to achieve a felicitous interpretation. These communicative advantages predict in turn an asymmetry in preference between the Simple-Present and the Present-Progressive markers in favor of the latter. This prediction is borne out by the variation pattern: across three Spanish dialectal varieties, the PresentProgressive marker is preferred over the Simple-Present marker to convey the progressive meaning regardless of context. This preference is particularly telling

alignment also obtains even though the ongoingness of the event is not at issue; that is, the perspective of the hearer is also brought closer to that of the speaker even if the event is not unfolding at reference time. We leave the analysis of these cases for further research. 
in the case of the Mexican Altiplano variety. In this variety, the Simple-Present marker no longer shows context sensitivity effects, suggesting that the Simple-Present marker is no longer able to participate in the achievement of perspective alignment even when the main components of this communicative goal are independently (nonlinguistically) provided by the shared perceptual access to the event between speaker and hearer. On the assumption that the Mexican Altiplano variety, like the other two varieties, showed these context effects at some previous point in its diachrony, the absence of context effects in the variety's modern instantiation suggests the resolution of a competition for the signaling of perspective alignment between the two markers; a competition that the Present-Progressive marker won. As it turns out, such a pattern is not idiosyncratic to Spanish. It is instead consistent with the well-attested cross-linguistic diachronic pattern of encroachment of Present-Progressive markers over the aspectual domain originally covered by Simple-Present markers (e.g., Bybee et al. 1994; Deo 2015).

Altogether, the approach to context structure presented here is consistent with a view of a relation between grammar and meaning that is mediated by generalized nonlinguistic communicative goals, such as perspective alignment, that can be lexically harnessed, that are at play during real-time language comprehension, and that link individualized usage patterns with the behavior of dialectal varieties and with generalized cross-linguistic patterns of change.

Acknowledgements We would like to thank both anonymous reviewers, and the audiences at HLS 2016, SNEWS 2016, Cognitive Structures 2016, CUNY 2017 and ICHL 2017 for comments and discussion about this work. All errors and omissions are our own. This research has been funded by NSF-INSPIRE Grant CCF-1248100, "The Underpinnings of Semantic Change: A Linguistic, Cognitive, and Information-Theoretic Investigation" to María Mercedes Piñango, Todd Constable, Ashwini Deo, and Mokshay Madiman.

\section{References}

Bertinetto, Pier Marco. (2000). The progressive in Romance, as compared with English. In Ö. Dahl (Ed.), Tense and aspect in the languages of Europe. (pp. 559-604). Berlin: de Gruyter.

Bybee, Joan, Perkins, Revere, \& Pagliuca, William. (1994). The evolution of grammar: Tense, aspect, and modality in the languages of the world. Chicago: UCP.

Comrie, Bernard. (1976). Aspect: An introduction to the study of verbal aspect and related problems. Cambridge: Cambridge University Press.

Dahl, Östen. (1985). Tense and Aspect Systems. Oxford: Basil Blackwell.

de Villiers, Jill. (2007). The interface of language and theory of mind. Lingua, 117, 1858-1878.

Deo, Ashwini. (2009). Unifying the imperfective and the progressive: Partitions as quantificational domains. Linguistics and Philosophy, 32, 475-521.

Deo, Ashwini. (2015). The semantic and pragmatic underpinnings of grammaticalization paths: The progressive to imperfective shift. Semantics and Pragmatics, 8, 1-52.

Dowty, David R. (1977). Towards a semantic analysis of verb aspect and the english 'imperfective' progressive. Linguistics and Philosophy, 1, 45-77.

Fuchs, Martín, Deo, Ashwini \& Piñango, María Mercedes. (2020). The progressive-to-imperfective shift: contextually determined variation in Rioplatense, Iberian, and Mexican Altiplano Spanish. 
In A. Morales-Front, M. J. Ferreira, R. P. Leow, \& C. Sanz (Eds.), Hispanic Linguistics. Current trends and new directions (pp. 119-136). Amsterdam: John Benjamins.

Gopnik, Alison. (1993). How we know our minds: the illusion of first-person knowledge of intentionality. Behavioral and Brain Sciences, 16, 1-15.

Kaplan, David. (1989). Demonstratives. In J. Almog, J. Perry, \& H. Wettstein (Eds.), Themes from Kaplan (pp. 481-563). New York: Oxford University Press.

Kurylowicz, Jerzy. (1964). The inflectional categories of Indo-European. Heidelberg: Carl Winter.

Lewis, David. (1980). Index, context, and content. In S. Kanger, \& S. Öhman (Eds.), Philosophy and grammar (pp. 79-100). Dordrecht: D. Reidel Publishing Company.

Marchand, Hans. (1955). On a question of aspect: A comparison between the progressive form in english and that in Italian and Spanish. Studia Lingüística, 9, 45-52.

NGRAE. Real Academia Española y Asociación de Academias de la Lengua Española. (2009). Las perífrasis verbales. Nueva Gramática de la Lengua Española. (pp. 2105-2222). Madrid: Espasa.

Roberts, Craige. (1996/2012). Information structure in discourse: Towards an integrated formal theory of pragmatics. In J. H. Yoon, \& A. Kathol (Eds.), Papers in Semantics, 49. Columbus, OH: Ohio State University Department of Linguistics. Semantics and Pragmatics, 5(6), 1-69.

Roberts, Craige. (2015). Indexicality: de se semantics and pragmatics. Ms. Ohio State University.

Stalnaker, Robert. (1978). Assertion. In P. Cole (Ed.), Pragmatics (pp. 315-332). New York: New York Academic Press.

Stalnaker, Robert. (2002). Common ground. Linguistics and Philosophy, 25, 701-721.

Vendler, Zeno. (1957). Verbs and times. Philosophical Review, 66(2), 143-160.

Verkuyl, Henk. (1972). On the compositional nature of the aspects. Dordrecht, Netherlands: Reidel. Wellman, Henry. (1990). The child's theory of mind. Cambridge, MA: MIT Press.

Yllera, Alicia. (1999). Las perífrasis verbales de gerundio y participio. In I. Bosque \& V. Demonte (Eds.), Gramática descriptiva de la lengua española (pp. 3390-3441). Madrid: Espasa.

Zipf, George K. (1949). Human behavior and the principle of least effort. Cambridge, MA: AddisonWesley Press.

Open Access This chapter is licensed under the terms of the Creative Commons Attribution 4.0 International License (http://creativecommons.org/licenses/by/4.0/), which permits use, sharing, adaptation, distribution and reproduction in any medium or format, as long as you give appropriate credit to the original author(s) and the source, provide a link to the Creative Commons license and indicate if changes were made.

The images or other third party material in this chapter are included in the chapter's Creative Commons license, unless indicated otherwise in a credit line to the material. If material is not included in the chapter's Creative Commons license and your intended use is not permitted by statutory regulation or exceeds the permitted use, you will need to obtain permission directly from the copyright holder.

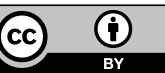

